\title{
THE RELATIONSHIP BETWEEN NUTRITIONAL STATUS, FUNCTIONAL CAPACITY, AND HEALTH-RELATED QUALITY OF LIFE IN OLDER ADULTS WITH TYPE 2 DIABETES: A PILOT EXPLANATORY STUDY
}

\author{
R.M. ALFONSO-ROSA ${ }^{1}$, B. DEL POZO-CRUZ1 ${ }^{1}$ J. DEL POZO-CRUZ1, \\ J.T. DEL POZO-CRUZ², B. SAÑUDO ${ }^{1}$
}

1. Department of Physical Education and Sports, University of Seville, Seville, Spain; 2. Department of Communication, University of Seville, Seville, Spain. Corresponding author: Borja del Pozo-Cruz. Email: bpozo@us.es.C/Pirotecnia s/n 41012 Seville, Seville, Spain.

\begin{abstract}
Objective: To explore the relationship between nutritional status, functional capacity and healthrelated quality of life (HRQoL) in older adults with type 2 diabetes (T2DM). Design: Cross-sectional study. Setting and participants: Forty two non-insulin dependent older adults from a primary care center in Seville, Spain. Measurements: Function was assessed with a battery of standardized physical fitness tests. Nutritional status was assessed using the Mini Nutritional Assessment (MNA) and the European Quality of Life Questionnaire (EQ-5D-3L) was used to assess HRQoL. Results: There was an association between MNAnutritional status and lower body strength as assessed by the chair sit-stand test $(r h o=.451 ; \mathrm{p}=.037)$ and between MNA-nutritional status and EQ-5D-3L-HRQoL (EQ-5D-3Lutility, rho= .553; $\mathrm{p}<.001$ and EQ-5D-3LVAS rho $=.402 ; \mathrm{p}<.001)$. An MNA item by item correlation analysis with HRQoL and lower limb strength demonstrated that HRQoL appears to be related to functional capacity (principally lower body strength, motor agility and cardiorespiratory fitness) among participants. These results were maintained when correlations were adjusted for co-morbidity. Conclusion: Our results demonstrated that nutritional status is moderately associated with HRQoL and lower limb strength in patients with T2DM. Our data suggest that more emphasis should be placed on interventions to encourage a correct diet and stress the needed to improve lower body strength to reinforce better mobility in T2DM population
\end{abstract}

Key words: Type 2 diabetes, management, exercise, physical fitness.

\section{Introduction}

Type 2 diabetes mellitus (T2DM) is a metabolic disorder characterized by hyperglycemia and insufficient secretion or action of endogenous insulin (1). Patients with T2DM are characterized by high adiposity and reduced fitness, which are also important predictors of Health-related Quality of Life (HRQoL) (2). Despite pharmacological strategies that can modulate many of the factors associated with the disease, T2DM-derived complications are common and have a significant impact in HRQoL, especially with respect to physical function (3) and depression (4). As the prevalence of T2DM is increasing within Europe (5), public health authorities should encourage the urgent implementation of both clinical and preventive intervention programmes to tackle the associated health and economic burden of the disease.

There is substantial evidence from multiple randomised controlled trials indicating that T2DM can be improved or at least controlled by lifestyle changes, including diet and physical fitness $(6,7)$. It was reported that malnutrition is prevalent among older adults with diseases such T2DM (8) affecting both physical function and psychological wellbeing, both of which are essential for satisfactory HRQoL (9). It is know that tissue sensitivity to insulin can be influenced by diet (10), however, tissue sensitivity to insulin (in addition to improvements in glycemic control) has also been reported to be influenced by improved function (11). It would be expected, therefore, to find a relationship between nutritional status and functional status Received May 22, 2012

Accepted for publication January 31, 2013 among those with T2DM. However, despite the evidence supporting lifestyle modifications to improve health outcomes in this population group, few studies have examined the relationship between nutritional status and functional status among people with T2DM (12), or whether or not these outcomes are related to HRQoL (13). The aim of this study therefore was to explore the relationship between nutritional status, functional capacity and HRQoL in older adults with T2DM.

\section{Method}

\section{Participants and study design}

A cross-sectional study was conducted. Patients were recruited (between April 1 and June 30 2011) from a local outpatient clinic (Seville, Spain). Out of 150 potentially eligible participants, 65 volunteers with a diagnosis of T2DM gave their written informed consent after receiving detailed information about the aims and study procedures. Exclusion criteria were: insulin dependency, history of cognitive impairment, severe heart, liver or kidney disease. In addition, those who answered "yes" to any question on the Physical Activities Readiness Questionnaire (indicating a possible contraindication for physical fitness testing) (14) were also excluded from the study. A total of 23 participants did not meet these criteria and were excluded from the study, resulting in a study sample of 42 patients (aged $70.3 \pm 7.0$ years) (Figure 1). The study was approved by the Ethics Committee of the University of Seville 
(Seville, Spain) and was conducted following the ethical guidelines of the Declaration of Helsinki.

\section{Procedures and Outcomes measures}

Participants were assessed on two separate occasions, $48 \mathrm{~h}$ apart. The first assessment consisted of questions on sociodemographic variables including age, gender as well as determining clinical predictor characteristic variables and health behaviours [alcohol, activity patterns (measured with the International Physical activity questionnaire (15)) and smoking]. Participants' weight, height, and waist and hip circumference were measured and body-mass index (BMI; $\mathrm{kg} / \mathrm{m} 2$ ) and waist to hip ratio were calculated. Body-fat percentage (BF \%) was also estimated using a handheld impedance analyzer (Omron BF-306, Omron Healthcare Europe BV, Hoofddorp, The Netherlands) according to the manufacturer's instructions (16). Mid-arm and mid-calf circumferences were also measured. The second part of the evaluation included assessing functional capacity, HRQoL, and a nutritional status assessment. The questionnaires and the assessment of the clinical predictor characteristic variables were performed by an experienced nurse who used these evaluations as part as her routine care for patients with T2DM. The functional capacity tests and the anthropometric assessment were performed by a professional fitness instructor, who had more than three years experience using the fitness battery used in this study. Neither the nurse nor the fitness instructors took part in the day to day running of the clinical trial or analysis of outcomes.

To assess functional capacity a battery of fitness tests previously validated in Spanish older adults, who were affected by chronic diseases, was used (17). This battery included the assessment of the lower body muscular strength by the 30second chair sit-stand test. Handgrip strength was evaluated by means of a manual dynamometer (TKK, Tokyo, Japan). The modified sit-and-reach test was used to measure the lower back and hip joint flexibility. The flexibility of the upper extremities was evaluated with a 'back scratch test'. Single-leg static balance was assessed with a "blind flamingo test" and the functional reach test. Motor agility/dynamic balance was assessed with the timed up and go test. Finally, to assess cardiovascular fitness the six-min walk test (6MWT) was used.

The EQ-5D-3L (18) assessed participants HRQoL. The EQ5D-3L includes five dimensions (mobility, personal care, usual activities, pain/discomfort and anxiety/depression), each of which has three levels (no problems, some problems, or extreme problems/unable to), answers ranging from 1 to 3 . The juxtaposition of the levels for these five dimensions correlates a to five-digit number, which reflect 243 possible health status values. These health status values can be collapsed to a health functional index or a 'utility', using time-trade off values (EuroQolutility; $1=$ full functional quality of life, $0=$ death). The EQ-5D-3L also includes a vertical 20-cm Visual Analogue Scale (VAS) which is used by participants to rate their own health between 0 (worst imaginable health state) and 100 (best imaginable health state), thereby providing an overall numerical estimate of their HRQoL (19).

The Mini Nutritional Assessment (MNA) tool was used to assess the nutritional status of our participants $(20,21)$. The MNA tool uses a scale ranging from 0 (the worst possible nutritional status) to 30 (the best possible nutritional status). The MNA tool has 18 items regarding food intake declination (1); weight loss (2); mobility (3); psychological stress or acute disease (4); neuropsychological problems (5); reduced BMI (6); living independently (7); taking more than three drugs per day (8); having skin ulcers (9); number of full meals per day (10); protein intake (11); fruit or vegetables intake (12); fluid intake (13); mood of feeding (14); self-reported nutritional status (15); health-status when compare with people of the same age (16); reduced mid-arm circumference (17) and calf circumference (18). For all items, the lower value indicates a worse score. Depending on the total MNA-score (sum of the items values), participants were classified into three possible nutritional status categories: well-nourished (MNA score $>24$ ), at risk of malnutrition (MNA score between 17 and 24) and malnourished (MNA score < 17).

\section{Statistical Analysis}

All statistical analyses were performed using the Statistical Package for Social Sciences (SPSS, v. 15.0 for WINDOWS, SPSS Inc., Chicago, IL, USA). Alpha value was set at .05 level for all test performed. Data are presented as means \pm standard deviation (SD), unless otherwise stated. One-way ANOVA with Bonferroni Post-Hoc test was performed to test the different between the MNA-based groups concerning the body composition variables. The association between nutritional status, functional status, body composition variables and HRQoL were analyzed using Spearman's correlation coefficients. Partial correlations adjusted for co-morbidity were also performed. The level of relationship was determined based on the recommendations of Cohen (22), a coefficient of between 0.1 and 0.29 was considered low; a coefficient between 0.3 and 0.49 were considered moderate and more than 0.5 was considered high. Additionally, we performed a linear regression analyses between these variables to get a better understanding of the associations identified.

\section{Results}

Table 1 outlines the socio-demographic characteristic, health habits, clinical, functional status, HRQoL and nutritional status of the participants in the study. Most participants reported that they did not smoke (93\%) or drink alcohol (80\%). Fifty per cent of participants reported a moderate physical activity level. Furthermore, $90 \%$ of participants were identified as being at risk of, or malnourished. 
Table 1

Characteristics of patients with type 2 diabetes $(n=42)$

\begin{tabular}{|c|c|}
\hline Variable & Value \\
\hline \multicolumn{2}{|l|}{ Socio-demographic characteristics } \\
\hline Age (years)* & $70.31(6.99)$ \\
\hline Gender, women (\%) & 45.20 \\
\hline \multicolumn{2}{|l|}{ Health habits } \\
\hline Smoking habit, no smoking (\%) & 92.90 \\
\hline Alcohol intake habit, no intake $(\%)$ & 78.60 \\
\hline \multicolumn{2}{|l|}{ Clinic and health characteristics } \\
\hline Drugs intake (number per day)* & $5.75(2.50)$ \\
\hline Illness (number)* & $2.71(1.20)$ \\
\hline Blood glucose level (mg/dL)* & $132.67(25.10)$ \\
\hline $\mathrm{SBP}(\mathrm{mmHg}) *$ & $149.75(22.20)$ \\
\hline $\mathrm{DBP}(\mathrm{mmHg}) *$ & $78.95(16.95)$ \\
\hline HR (bpm)* & $74.06(14.80)$ \\
\hline Diabetes duration (years)* & $7(2.30)$ \\
\hline \multicolumn{2}{|l|}{ Activity patterns (IPAQ) } \\
\hline Vigorous physical activity level (MET min/week)* & $80.00(365.96)$ \\
\hline Moderate physical activity level (MET min/week)* & $1188.57(1273.50)$ \\
\hline Walking physical activity level (MET min/week)* & $2475.00(7690.88)$ \\
\hline Total physical activity level (MET min/week)* & 3743.57 (7777.96) \\
\hline Sedentary habit (time sited) (min/week)* & $2292.85(1006.48)$ \\
\hline High physical activity level (\%) & 23.80 \\
\hline Moderate physical activity level (\%) & 52.40 \\
\hline Low physical activity level (\%) & 23.80 \\
\hline \multicolumn{2}{|l|}{ Functional capacity } \\
\hline Dominant-handgrip strength $(\mathrm{Kg})^{*}$ & $27.45(10.5)$ \\
\hline Chair sit and reach $(\mathrm{cm})^{*}$ & $18.26(4.97)$ \\
\hline Right-back scratch test $(\mathrm{cm})^{*}$ & $-9.28(17.20)$ \\
\hline Left-back scratch test $(\mathrm{cm})^{*}$ & $-11.51(19.40)$ \\
\hline Functional reach $(\mathrm{cm})^{*}$ & $28.00(6.30)$ \\
\hline Chair sit-stand test (No. of stands)* & $13.85(2.90)$ \\
\hline 30-second eye-open, single-leg flamingo test (failures)* & $2.41(2.30)$ \\
\hline TUG (second)* & $9.48(4.12)$ \\
\hline 6MWT $(\mathrm{m})^{*}$ & $501.87(110.50)$ \\
\hline \multicolumn{2}{|l|}{ Health-Related Quality of Life (EQ-5D-3L) } \\
\hline Mobility, problems (\%) & 21.40 \\
\hline Personal care, problems $(\%)$ & 9.50 \\
\hline Daily tasks, problems (\%) & 26.20 \\
\hline Pain/Discomfort, problems (\%) & 54.80 \\
\hline Anxiety/ Depression, problems (\%) & 52.40 \\
\hline EQ-5D-3Lutility (points)* & $0.57(0.30)$ \\
\hline VAS $(\mathrm{mm})^{*}$ & $71.08(13.60)$ \\
\hline \multicolumn{2}{|l|}{ Nutritional status (MNA) } \\
\hline MNA (points)* & $19.97(2.57)$ \\
\hline \multicolumn{2}{|l|}{ Risk of malnutrition } \\
\hline Well-nourished n (\%) & $3(7.1)$ \\
\hline At risk of malnutrition $\mathrm{n}(\%)$ & $33(78.60)$ \\
\hline Malnourished n (\%) & $6(14.30)$ \\
\hline
\end{tabular}

*: Values expressed as Mean (SD); SBP: Systolic Blood Pressure; DBP: Diastolic Blood Pressure; HR: Heart Rate; IPAQ: International Physical Activity Questionnaire; Sedentary habit: time seated per week; MET: metabolic equivalent; TUG: Time up and go test; 6MWT: 6-minute walking test; EQ-5D-3Lutility: utility index from Time trade off method in the European Quality of Life Questionnaire (0 to 1 point); VAS: Visual Analogic Scale from EQ-5D-3L questionnaire (0 to $100 \mathrm{~mm}$ ); MNA: mini-nutritional assessment tool (0 to 30).
Table 2 shows the anthropometric characteristics across the different MNA-status groups. The "malnourished" group of patients had a statistically significant decrease in their BMI when compared with the patients allocated in the "at risk of malnutrition" group $(\mathrm{p}=0.009)$ and had greater waist to hip ratio when compared to the "well-nourished" group of patients $(\mathrm{p}=0.05)$. For patients in the "malnourished" group there was a trend towards lower weight, and smaller mild-arm and calf circumferences when compared to both the "well-nourished" and "at risk of malnutrition" groups of patients; however, these differences did not reach statistical significance. There was a correlation between BMI and MNA among participants (rho= $.385, \mathrm{p}=0.039)$, which remained after correction for comorbidity $(\mathrm{rho}=.389, \mathrm{p}=0.041)$. A correlation between waist to hip ratio and MNA was found only after performing the correction for co-morbidity $(\mathrm{rho}=-.355, \mathrm{p}=0.050)$.

Figure 1

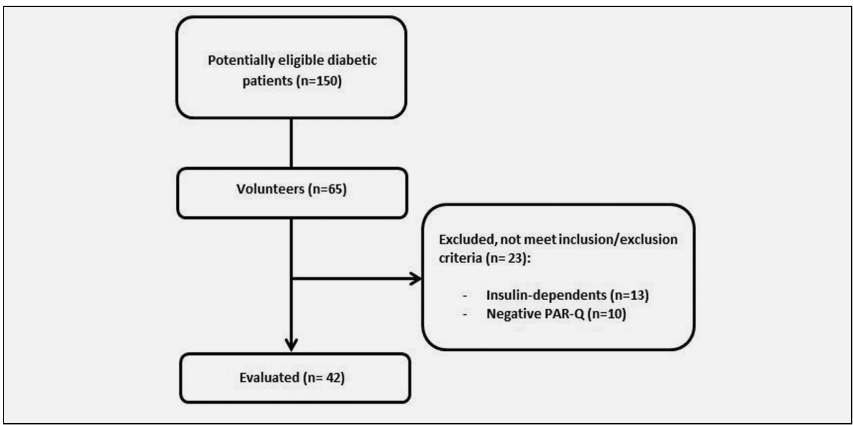

Spearman's correlation coefficients and partial correlations between nutritional status (MNA) and physical-fitness in those with T2DM demonstrated (table 3), a moderate positive association between MNA-nutritional status and lower body strength as assessed by the chair stand test (rho $=.451 ; \mathrm{p}=$ $0.037)$. This correlation held even when adjusted for comorbidity ( $r h o=.431 ; \mathrm{p}=0.041)$. Despite the aforementioned association, no statistical significant associations were found between physical fitness tests and MNA-nutritional status. Regression analyses performed (Figure 2) confirm the moderate association between the lower limb strength and MNA total score $(\mathrm{R} 2=.12 ; \mathrm{p}=0.005)$. Moreover, a moderate positive association was found between protein intake and fruit

Table 2

Description of participants' body composition variables $(n=42)$

\begin{tabular}{|c|c|c|c|c|c|}
\hline Body composition variables & Total sample $(n=42)$ & Well-nourished $(n=3)$ & At risk of malnutrition $(n=33)$ & Malnourished $(n=6)$ & $\mathbf{p}^{\mathbf{a}}$ \\
\hline Weight (Kg) & 75.03 (11.99) & $71.05(28.68)$ & $76.61(10.98)$ & $67.95(9.34)$ & 0.379 \\
\hline $\mathrm{BMI}\left(\mathrm{Kg} / \mathrm{m}^{2}\right)$ & $27.77(6.60)$ & $26.50(4.68)$ & $29.42(3.94)$ & $18.93(12.86)$ & 0.009 \\
\hline $\mathrm{BF} \%$ & $35.40(7.40)$ & $27.10(4.68)$ & $36.80(7.63)$ & $31.90(1.18)$ & 0.123 \\
\hline WHR & $0.94(0.09)$ & $0.80(0.14)$ & $0.95(0.09)$ & $0.97(0.05)$ & 0.050 \\
\hline Mid-arm circumference $(\mathrm{cm})$ & $30.34(8.7)$ & $28.01(4.68)$ & $30.69(3.08)$ & $27.50(2.38)$ & 0.443 \\
\hline Calf circumference $(\mathrm{cm})$ & $36.12(5.01)$ & $36.02(4.24)$ & $36.63(5.03)$ & $34.25(5.90)$ & 0.670 \\
\hline
\end{tabular}

Values expressed as Mean (SD); BMI: Body mass index; BF\%: Body-fat percentage WHR: Waist-to-hip ratio; pa: p value from one way ANOVA with Bonferroni post-hoc test (values Values expressed as Mean (SD); BMI: Body mass index; BF\%: Body-fat percentage WHR: Waist-to-hip ratio; pa: p value from one way ANOVA with Bonferroni post-hoc test (values
in bold: statistically significant differences were found between malnourished patients and those at risk of malnutrition and between well-nourished patients and malnourished patients) 
and vegetable intake (items 11 , and 12 of the MNA tool) and the lower limb strength with a rho $=.399 ; \mathrm{p}=0.004$ and $\mathrm{rho}=$ $.415 ; \mathrm{p}=0.028$ respectively. When the correlation was adjusted by relevant co-morbidity these relationships held ( $\mathrm{rho}=.315$; $\mathrm{p}=$ 0.049 for item 11 and $\mathrm{rho}=.387 ; \mathrm{p}=0.042$ for item 12) (Table 4).

\section{Figure 2}

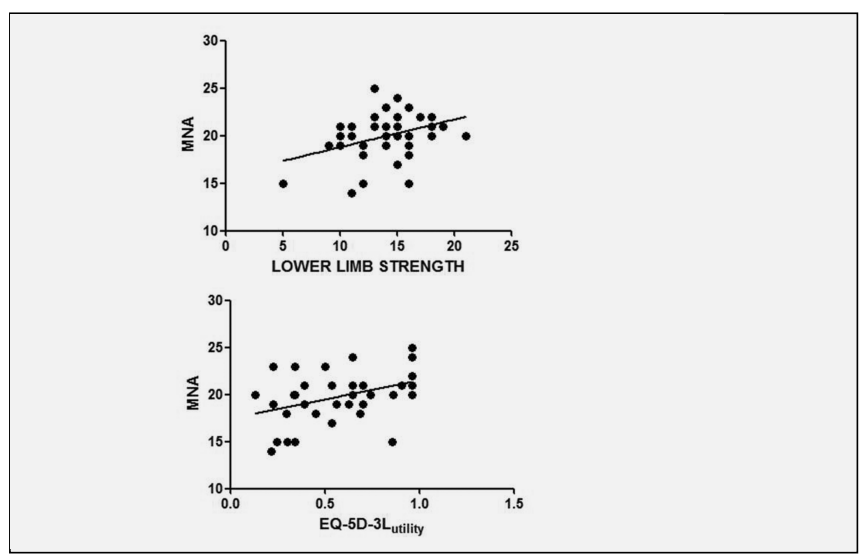

All EQ-5D-3L dimensions were associated with the MNAnutritional status (Table 3). A moderate negative relationship was found between all EQ-5D-3L dimensions and MNAnutritional status (mobility, rho $=-.315, \mathrm{p}<0.001$; personal care, rho $=-.316, \mathrm{p}=0.005$; daily tasks, rho $=-.378, \mathrm{p}=$ pain/discomfort, $r h o=-.329, \mathrm{p}<0.001)$. A strong negative relationship between anxiety/depression EQ-5D-3L dimension and MNA-nutritional status, was found $(\mathrm{rho}=-.533, \mathrm{p}<.001)$. Also, a strong positive relationship between EQ-5D-3Lutility and MNA-nutritional status $(\mathrm{rho}=.553, \mathrm{p}<0.001)$ and between EQ-5D-3LVAS and MNA-nutritional status (rho= .402 , $\mathrm{p}<0.001$ ) was reported. With the exception of the personal care dimension and the EQ-5D-3LVAS, the relationship was also maintained after adjusting the correlation analysis for comorbidity. Regression analyses (Figure 2) confirmed this relationship $(\mathrm{R} 2=.20 ; \mathrm{p}=0.004)$. Results from the correlation analysis between the items from the MNA and the five dimensions from the EQ-5D-3L are also presented in Table 4.

Table 5 demonstrates spearman's correlation coefficients and partial correlations (adjusted for co-morbidity) between functional status and HRQoL. Lower body strength was moderately (anxiety/depression, rho $=-.496, \mathrm{p}=0.037$ and EQ$5 \mathrm{D}-3$ Lutility, rho $=.464, \mathrm{p}=0.014$ ) to highly (mobility, rho $=$ $.581, \mathrm{p}<0.001$; personal care, $\mathrm{rho}=-.701, \mathrm{p}<0.001$; pain/discomfort, rho: $-.572, \mathrm{p}<0.001$ and VAS, $r h o=638$, $\mathrm{p}<0.001$ ) associated with all dimensions of EQ-5D-3L, with the exception of the daily tasks dimension. There was a strong negative relationship between cardiorespiratory fitness and some HRQoL dimensions (mobility, rho=.-916, $\mathrm{p}<.001$ and personal care, $r h o=-.922, \mathrm{p}=0.041)$. Finally dynamic balance was correlated with HRQoL (mobility, rho= -.598, p<.001; pain/discomfort, rho $=-.572, \mathrm{p}=.005$; anxiety/depression, $\mathrm{rho}=-$
$.496, \mathrm{p}=0.034$, EQ-5D-3Lutility, rho $=.414, \mathrm{p}=0.023$ and VAS, $\mathrm{rho}=.538, \mathrm{p}<0.001)$. After adjusting the correlation analysis for relevant co-morbidity, these relationships were maintained in most cases.

\section{Table 3}

Spearman's correlation coefficients and Partial correlations (adjusted by co-morbidity) between nutritional status assessed with MNA tool and functional capacity or EQ-5D-3L-HealthRelated Quality of Life in the type 2 diabetic patients $(n=42)$

\begin{tabular}{lc}
\hline Functional capacity variables & $M N A$ \\
Dominant-handgrip strength $(\mathrm{Kg})$ & .142 \\
Chair sit and reach $(\mathrm{cm})$ & -.068 \\
Right-back scratch test $(\mathrm{cm})$ & -.107 \\
Left-back scratch test $(\mathrm{cm})$ & .128 \\
Functional reach $(\mathrm{cm})$ & -.303 \\
Chair sit-stand test (No. of stands) & $.451^{* \mathrm{a}}$ \\
30-second eye-open single-leg flamingo test (failures) & .176 \\
TUG (second) & -.245 \\
6MWT (m) & .582 \\
Health-Related Quality of life (EQ-5D-3L) & \\
Mobility & $-.315^{* \mathrm{~b}}$ \\
Personal care & $-.316^{*}$ \\
Daily tasks & $-.378^{* \mathrm{c}}$ \\
Pain/Discomfort & $-.329^{* \mathrm{~d}}$ \\
Anxiety/ Depression & $-.533^{* * \mathrm{e}}$ \\
EQ-5D-3Lutility (points) & $.553^{* * \mathrm{f}}$ \\
VAS (mm) & $.402^{*}$ \\
\hline
\end{tabular}

TUG: Time up and go test; 6MWT: 6-minute walking test; EQ-5D-3Lutility: utility index from Time trade off method in the European Quality of Life Questionnaire (0 to 1 point); VAS: Visual Analogic Scale from EQ-5D-3L questionnaire (0 to $100 \mathrm{~mm})$; MNA: mininutritional assessment tool ( 0 to 30 points); $* \mathrm{p}<.05$; ** $\mathrm{P}<0.01$; a. Partial correlation is significant at $\mathrm{p}<0.05(\mathrm{r}=.431)$; b. Partial correlation is significant at $\mathrm{p}<0.05(\mathrm{r}=-.294)$; $\mathrm{c}$. Partial correlation is significant at $\mathrm{p}<0.05(\mathrm{r}=-.359)$; d. Partial correlation is significant at $\mathrm{p}<0.05(\mathrm{r}=-.432)$; e. Partial correlation is significant at $\mathrm{p}<0.05(\mathrm{r}=-.441)$; f. Partial correlation is significant at $\mathrm{p}<0.01(\mathrm{r}=-.434)$

\section{Discussion}

Although the risk of malnutrition and inactivity is expected to be more prevalent in elderly than in younger adults, it is also an important consideration when a disease such as diabetes is present (23). For older adults with T2DM, regular physical activity and a correct diet could result in better disease control and an increase in HRQoL. Unfortunately, little is known regarding the relationship between these outcomes among this population group. Therefore the aim of the current study was to gain a better understanding of the relationship between nutritional status, HRQoL and functional capacity among 60-83 older adults with T2DM.

The main finding of our study was that MNA-nutritional status was associated with both EQ-5D-3L-HRQoL dimensions and lower limb strength in T2DM subjects. One of the novel aspects of this study was that we assessed the relationship between these outcomes in the same group of patients, giving a better understanding of these outcomes in T2DM patients.

Our results show a trend to reduction in the most of the important anthropometric measurements for nutritional status 
Table 4

Spearman's correlation coefficients and Partial correlations (adjusted for co-morbidity) between nutritional status assessed with MNA tool (items) and EQ-5D-3L-Health-Related Quality of Life dimensions or lower limb strength in patients with type 2 diabetes $(n=42)$

\begin{tabular}{|c|c|c|c|c|c|c|}
\hline \multirow[b]{2}{*}{ MNA Items } & \multicolumn{5}{|c|}{ Health-Related Quality of life dimensions (EQ-5D-3L) } & \multirow[b]{2}{*}{ Lower Limb Strength } \\
\hline & Mobility & Personal care & Daily Tasks & Pain/Discomfort & Anxiety/Depression & \\
\hline MNA1 & $-.335^{* a}$ & ns & ns & $-.360 * \mathrm{f}$ & ns & ns \\
\hline MNA2 & ns & ns & ns & ns & ns & ns \\
\hline MNA3 & $-.215^{*}$ & ns & $-.379 *$ & ns & ns & ns \\
\hline MNA4 & ns & ns & ns & ns & ns & ns \\
\hline MNA5 & ns & ns & $\mathrm{ns}$ & ns & $-.543^{* \mathrm{f}}$ & ns \\
\hline MNA6 & ns & ns & ns & ns & ns & ns \\
\hline MNA8 & ns & ns & $\mathrm{ns}$ & ns & $\mathrm{ns}$ & ns \\
\hline MNA9 & $-.417 * *$ & $-.472 * *$ & $-.594 * \mathrm{c}$ & ns & ns & ns \\
\hline MNA10 & $\mathrm{ns}$ & $\mathrm{ns}$ & $.308 * \mathrm{~d}$ & ns & ns & ns \\
\hline MNA11 & $-.500 * *$ & $-.337 *$ & ns & ns & $\mathrm{ns}$ & $.399^{* \mathrm{~g}}$ \\
\hline MNA12 & ns & $\mathrm{ns}$ & ns & ns & ns & $.415^{* \mathrm{~h}}$ \\
\hline MNA13 & ns & ns & $-.334 *$ &.$-416 * *$ & $\mathrm{~ns}$ & ns \\
\hline MNA14 & $\mathrm{ns}$ & ns & $-.340 * \mathrm{e}$ & $\mathrm{ns}$ & $-.428 * *$ & ns \\
\hline MNA15 & $\mathrm{ns}$ & ns & $-.390 *$ & ns & ns & ns \\
\hline MNA17 & $\mathrm{ns}$ & ns & $\mathrm{ns}$ & ns & $\mathrm{ns}$ & ns \\
\hline MNA18 & $\mathrm{ns}$ & ns & $\mathrm{ns}$ & $\mathrm{ns}$ & $\mathrm{ns}$ & $\mathrm{ns}$ \\
\hline
\end{tabular}

${ }^{*} \mathrm{p}<0.05 ; * * \mathrm{p}<0.01$; Values in bold denote that only a partial correlation exists; a. Partial correlation is significant at $\mathrm{p}<0.01(\mathrm{r}=-.775)$; $\mathrm{b}$. Partial correlation is significant at $\mathrm{p}<0.05(\mathrm{r}=$ $.490)$; c. Partial correlation is significant at $\mathrm{p}<0.05(\mathrm{r}=-.594)$; d. Partial correlation is significant at $\mathrm{p}<0.05(\mathrm{r}=-.497)$; e. Partial correlation is significant at $\mathrm{p}<0.05(\mathrm{r}=-.736)$; f. Partial correlation is significant at $\mathrm{p}<0.01(\mathrm{r}=-.432)$; g. Partial correlation is significant at $\mathrm{p}<0.05(\mathrm{r}=.315)$; $\mathrm{h}$. Partial correlation is significant at $\mathrm{p}<0.05(\mathrm{r}=.387)$

Table 5

Spearman's correlation coefficients and Partial correlations (adjusted by co-morbidity) between functional capacity and HealthRelated Quality of Life assessed with EQ-5D-3L in patients with type 2 diabetes $(n=42)$

\begin{tabular}{|c|c|c|c|c|c|c|c|}
\hline \multirow[b]{2}{*}{ Functional capacity variables } & \multirow[b]{2}{*}{ Mobility } & \multicolumn{3}{|c|}{ EQ-5D-3L dimensions } & \multirow[b]{2}{*}{$\begin{array}{l}\text { Anxiety/ } \\
\text { Depression }\end{array}$} & \multirow[b]{2}{*}{ EQ-5D-3Lutility } & \multirow[b]{2}{*}{ VAS } \\
\hline & & Personal care & Daily Tasks & Pain/Discomfort & & & \\
\hline Dominant-handgrip strength $(\mathrm{Kg})$ & -.253 & $-.398 * a$ & -.290 & $-.379 *$ & .003 & -.208 & -.176 \\
\hline Chair sit and reach $(\mathrm{cm})$ & -.068 & -.339 & .154 & .051 & -.202 & .153 & .423 \\
\hline Right-back scratch test (cm) & .100 & .240 & .006 & .081 & .266 & $-.409 *$ & -.196 \\
\hline Left-back scratch test $(\mathrm{cm})$ & -.143 & .039 & -.316 & -.373 & .075 & .038 & -.169 \\
\hline Functional reach $(\mathrm{cm})$ & .189 & .378 & .030 & .040 & .204 & -.222 & .219 \\
\hline Chair sit-stand test (No. of stands) & $-.581 * * \mathrm{~b}$ & $-.701 * *_{\mathrm{c}}$ & -.406 & $-.572 * * d$ & $-.496^{*}$ & $.464^{*}$ & $.638 * *_{e}$ \\
\hline $\begin{array}{l}\text { 30-second eye-open single-leg } \\
\text { flamingo test (failures) }\end{array}$ & -.086 & -.139 & .282 & $.511^{*}$ & .085 & -.213 & .024 \\
\hline TUG (second) & $.598 * *_{\mathrm{f}}$ & .417 & -.406 & $-.572 * *$ & $-.496^{*}$ & $.414^{*}$ & $.538 * *$ \\
\hline 6MWT (m) & $-.916 * * \mathrm{~g}$ & $-.922 *$ & -.916 & -.911 & -.679 & .924 & -.834 \\
\hline
\end{tabular}

TUG: Time up and go test; 6MWT: 6-minute walking test; EQ-5D-3Lutility: utility index from Time trade off method in the European Quality of Life Questionnaire (0 to 1 point); VAS: Visual Analogic Scale from EQ-5D-3L questionnaire (0 to 100mm); ${ }^{*} \mathrm{p}<0.05 ; * * \mathrm{p}<0.01$; a. Partial correlation is significant at $\mathrm{p}<0.05$ ( $\left.\mathrm{r}=-.364\right)$; b. Partial correlation is significant at $\mathrm{p}<0.05(\mathrm{r}=-.560)$; . Partial correlation is significant at $\mathrm{p}<0.05(\mathrm{r}=-.653)$; d. Partial correlation is significant at $\mathrm{p}<0.05(\mathrm{r}=-.478)$; e. Partial correlation is significant at $\mathrm{p}<0.05(\mathrm{r}=.536)$; f. Partial correlation is significant at $\mathrm{p}<0.05(\mathrm{r}=.532)$; g. Partial correlation is significant at $\mathrm{p}<0.05(\mathrm{r}=-.907)$

determination (24), thus supporting the relationship found between BMI or waist to hip ratio and the MNA-score within our group of patients (25). However, the fact that most patients were in the "at risk of malnutrition" group, along with the small sample size (i.e. few patients in the other two groups), meant that it was unlikely that differences would be found in other anthropometric measurements. Moreover, it should also be remembered that the MNA is a global nutritional assessment tool, thus covering all areas of nutritional evaluation.

Functional capacity of those with T2DM appears to be reduced when compared with those without T2DM $(26,27)$, our results regarding related variables are similar to those found in previous studies. Ozdirenc et al. (26) compared 30 adults withT2DM to 30 adults without T2DM and found a decrease in 
lower body strength, balance and cardiorespiratory fitness in those with T2DM. Ijzeman et al. also confirmed decreased lower limb strength and impaired mobility in patients with T2DM with polyneuropathy (27). Similar impairments may be a possible explanation for the lower functional capacity reported by our participants, which has been also reported to play an important role in HRQoL among T2DM patients (9).

Previous work has identified many dietetic problems in older adults with T2DM $(28,29)$ and our finding on nutritional status ( $85.7 \%$ at risk of being malnourished) support this previous work. In this specific population, malnutrtional status is related to the glycemic control, such the glycemic index of nutrients $(28,29)$ or reduced Zinc and Vitamin C levels $(30)$. The poor nutritional status exhibited by those with T2DM is a barrier to gaining muscle tissue and strength, which may be also related to poor insulin tissue sensitivity (10). This could be, at least in part, a possible explanation for the relationship found between nutritional status and lower body muscle strength in our subjects, and supported by our MNA item by item correlation analysis, were a poor diet (MNA items 11 and 12) seems to be related to lower limb muscle strength. Different studies on older adults have reported a negative association between daily dietary intake of antioxidants, physical performance and lower limb muscle strength, (31) even in younger older adults (32). Moreover, Turnbull et al. (12) reaffirm this relationship among adults with T2DM.

The negative effects of poor diet on muscle mass and function also negatively affect glycemic control. When such diet is present among older adults there is a high probability of sarcopenia (lack of muscle mass), thus affecting the functionality of individuals (33). Although we could not measure sarcopenia among our patients, the relationship found between lower muscle strength and a poor protein diet (MNA item 11) in our participants would account for the lack of function, hence affecting HRQoL. Thus, increases in skeletal muscle mass, or even muscle function (34) are not only related to glycemic control $(35,36)$ but it also appears to be important for prevent the decline in function among T2DM patients, particularly with aging. Consequently, efforts should be made to increase physical exercise, which may lead to improvements in muscle strength, in the T2DM population.

In the current study nutritional status was associated with all EQ-5D-3L dimensions, even though no previous work has been found that assessed this relationship among T2DM patients, our results are consistent with other reports which have examined nutrition and HRQoL in a smaller community-based study (37), in other selected older adults populations (38) and a population sample studies in older adults (39). The findings from our study and the cited work strengthened our understanding of the relationship between the risk for malnutrition and reduced HRQoL. As mentioned, malnutrition plays an important role in muscle function (40) but may also have had an important impact on HRQoL, considering that all EQ-5D-3L dimensions were significantly associated with the patient' nutritional status in the present study. Moreover, poor nutritional status could negatively affect the mental health of older adults worsening their HRQoL (39). This relationship was also confirmed in the current study as EQ-5D-3L anxiety/depression dimension was associated with the poor nutritional status. Although the correlation coefficient between HRQoL dimensions and MNA seems to decrease when the correlation analysis was controlled for relevant co-morbidity, this relationship is perhaps given further support when we note the relationship between the items from the MNA and the different dimensions from the EQ-5D-3L. These results appear to be in agreement with different studies that report a clear reduction in HRQoL in those patients with T2DM and associated co-morbidity (41); especially with respect to mobility, self-care and the usual daily activities dimensions of the EQ-5D-3L dimensions (42). However, because the MNA tool was used as a screening tool for risk of malnutrition in our study, self-reported health status questions included in this tool may contribute to extent of the relationship between HRQoL and nutritional status.

Several limitations need to be recognised in this study. Since a cross-sectional design was used, a causative interpretation is not possible. Another limitation was the use of the EQ-5D-3L, which is a very general HRQoL instrument. It is important to be aware that because the EQ-5D-3L is not diabetes specific it may reflect problems related to other conditions or sub estimate or overestimate the real self-reported health status. Despite this, the use of a general HRQoL instrument allows us to compare with other conditions. Another shortcoming is that the population of this study represents a convenience sample defined by the inclusion criteria, which may introduce selection bias. Moreover, a risk of self-selection bias needs to be recognized since we were obviously not able to obtain data on non-participants, due to the voluntary nature of the study. Therefore, given the small sample size of our study it is difficult to give definitive conclusions but the results give us an indication of what further research may show. Future larger prospective cohort studies are required to confirm the relationships demonstrated in the current study. Longitudinal studies implementing lifestyle interventions including diet and exercise, designed to increase physical fitness (mainly muscle strength) are also warranted to clarify the relationships between the effects of such interventions on these outcomes.

Despite these limitations, to our knowledge this is the first study analyzing the relationship between the two main components of lifestyle interventions, (i.e. diet and physical function), therefore helping to progress the understanding of the management of patients with T2DM. In conclusion our results have shown that nutritional status is moderately associated with HRQoL and lower limb strength, which is also associated with HRQoL in patients with T2DM. Physical activity and diet are the cornerstones in the prevention and treatment of T2DM (6, 43-45); Our data suggest that in the future more emphasis could be placed on interventions to enhance a correct diet through early identification of the risk for malnutrition and stress the 


\section{JNHA: NUTRITION}

needed to improve lower body strength to reinforce better mobility in T2DM population.

Conflict of interest: Rosa M. Alfonso-Rosa, Jesus del Pozo-Cruz, Jose del Pozo-Cruz, Borja Sañudo Corrales and Borja del Pozo-Cruz have no conflict of interest to declare.

\section{References}

1. Maritim AC, Sanders RA, Watkins JB, 3rd. Diabetes, oxidative stress, and antioxidants: a review. J Biochem Mol Toxicol. 2003;17(1):24-38.

2. Sundaram M, Kavookjian J, Patrick JH, Miller LA, Madhavan SS, Scott VG. Quality of life, health status and clinical outcomes in Type 2 diabetes patients. Qual Life Res. 2007 Mar;16(2):165-77

3. Gough SC, Kragh N, Ploug UJ, Hammer M. Impact of obesity and type 2 diabetes on health-related quality of life in the general population in England. Diabetes Metab Syndr Obes. 2009;2:179-84.

4. Egede LE, Ellis C. Diabetes and depression: global perspectives. Diabetes Res Clin Pract. 2010 Mar;87(3):302-12.

5. Age- and sex-specific prevalences of diabetes and impaired glucose regulation in 13 European cohorts. Diabetes Care. 2003 Jan;26(1):61-9.

6. Tuomilehto J, Lindstrom J, Eriksson JG, Valle TT, Hamalainen H, Ilanne-Parikka P, et al. Prevention of type 2 diabetes mellitus by changes in lifestyle among subjects with impaired glucose tolerance. N Engl J Med. 2001 May 3;344(18):1343-50.

7. Knowler WC, Barrett-Connor E, Fowler SE, Hamman RF, Lachin JM, Walker EA, et al. Reduction in the incidence of type 2 diabetes with lifestyle intervention or metformin. N Engl J Med. 2002 Feb 7;346(6):393-403.

8. Pinget M. [Epidemiology of type 2 diabetes, is it a problem of bad nutrition or malnutrition?]. Soins. 2008 Apr(724 Suppl):S4-8.

9. Kujala UM. Evidence on the effects of exercise therapy in the treatment of chronic disease. Br J Sports Med. 2009 Aug;43(8):550-5.

10. Rolland Y, Czerwinski S, Abellan Van Kan G, Morley JE, Cesari M, Onder G, et al. Sarcopenia: its assessment, etiology, pathogenesis, consequences and future perspectives. J Nutr Health Aging. 2008 Aug-Sep;12(7):433-50.

11. Srikanthan P, Karlamangla AS. Relative muscle mass is inversely associated with insulin resistance and prediabetes. Findings from the third National Health and Nutrition Examination Survey. J Clin Endocrinol Metab. 2011 Sep;96(9):2898-903.

12. Turnbull PJ, Sinclair AJ. Evaluation of nutritional status and its relationship with functional status in older citizens with diabetes mellitus using the mini nutritional assessment (MNA) tool--a preliminary investigation. J Nutr Health Aging. 2002 May;6(3):185-9.

13. Bennett WL, Ouyang P, Wu AW, Barone BB, Stewart KJ. Fatness and fitness: how do they influence health-related quality of life in type 2 diabetes mellitus? Health Qual Life Outcomes. 2008;6:110.

14. Thomas S, Reading J, Shephard RJ. Revision of the Physical Activity Readiness Questionnaire (PAR-Q). Can J Sport Sci. 1992 Dec;17(4):338-45.

15. Craig CL, Marshall AL, Sjostrom M, Bauman AE, Booth ML, Ainsworth BE, et al International physical activity questionnaire: 12-country reliability and validity. Med Sci Sports Exerc. 2003 Aug:35(8):1381-95.

16. Deurenberg P, Andreoli A, Borg P, Kukkonen-Harjula K, de Lorenzo A, van Marken Lichtenbelt $\mathrm{WD}$, et al. The validity of predicted body fat percentage from body mass index and from impedance in samples of five European populations. Eur J Clin Nutr. 2001 Nov;55(11):973-9.

17. Gusi N, Prieto J, Olivares PR, Delgado S, Quesada F, Cebrián C. Normative Fitnes Performance Scores of Community-Dwelling Older Adults in Spain. J Aging Phys Act. 2011;In press

18. EuroQol--a new facility for the measurement of health-related quality of life. The EuroQol Group. Health Policy. 1990 Dec;16(3):199-208.

19. Brooks R. EuroQol: the current state of play. Health Policy. $1996 \mathrm{Jul} ; 37(1): 53-72$.

20. Guigoz Y, Vellas BJ. [Malnutrition in the elderly: the Mini Nutritional Assessment (MNA)]. Ther Umsch. 1997 Jun;54(6):345-50.

21. Guigoz Y, Vellas B, Garry PJ. Assessing the nutritional status of the elderly: The Mini Nutritional Assessment as part of the geriatric evaluation. Nutr Rev. 1996 Jan:54(1 Pt 2):S59-65.

22. Cohen J. Statistical power analysis for the behavioural sciences. 2nd ed. Hillsdale,
NJ: Lawrence Erlbaum Publishers; 1988

23. Hughes S. Diabetes: support for those at risk of malnutrition in the community. $\mathrm{Br}$ Community Nurs. 2012 Nov;17(11):529-30, 32-4.

24. Forster S, Gariballa S. Age as a determinant of nutritional status: a cross sectional study. Nutr J. 2005;4:28

25. Sanchez-Garcia S, Garcia-Pena C, Duque-Lopez MX, Juarez-Cedillo T, CortesNunez AR, Reyes-Beaman S. Anthropometric measures and nutritional status in a healthy elderly population. BMC Public Health. 2007;7:2.

26. Ozdirenc M, Biberoglu S, Ozcan A. Evaluation of physical fitness in patients with Type 2 diabetes mellitus. Diabetes Res Clin Pract. 2003 Jun;60(3):171-6.

27. TH IJ, Schaper NC, Melai T, Meijer K, Willems PJ, Savelberg HH. Lower extremity muscle strength is reduced in people with type 2 diabetes, with and without polyneuropathy, and is associated with impaired mobility and reduced quality of life. Diabetes Res Clin Pract. 2012 Mar;95(3):345-51.

28. Krishnan S, Rosenberg L, Singer M, Hu FB, Djousse L, Cupples LA, et al. Glycemic index, glycemic load, and cereal fiber intake and risk of type 2 diabetes in US black women. Arch Intern Med. 2007 Nov 26;167(21):2304-9.

29. Willett W, Manson J, Liu S. Glycemic index, glycemic load, and risk of type 2 diabetes. Am J Clin Nutr. 2002 Jul;76(1):274S-80S

30. Reed RL, Mooradian AD. Nutritional status and dietary management of elderly diabetic patients. Clin Geriatr Med. 1990 Nov;6(4):883-901.

31. Cesari M, Pahor M, Bartali B, Cherubini A, Penninx BW, Williams GR, et al. Antioxidants and physical performance in elderly persons: the Invecchiare in Chianti (InCHIANTI) study. Am J Clin Nutr. 2004 Feb;79(2):289-94

32. Bischoff-Ferrari HA, Dietrich T, Orav EJ, Hu FB, Zhang Y, Karlson EW, et al. Higher 25-hydroxyvitamin D concentrations are associated with better lowerextremity function in both active and inactive persons aged $>$ or $=60 \mathrm{y}$. Am J Clin Nutr. 2004 Sep;80(3):752-8.

33. Cruz-Jentoft AJ, Landi F, Topinkova E, Michael JP. Understanding sarcopenia as a geriatric syndrome. Current Opinion in Clinical Nutrition and Metabolic Care. 2010;13(1):1-7.

34. Zanuso S, Jimenez A, Pugliese G, Corigliano G, Balducci S. Exercise for the management of type 2 diabetes: a review of the evidence. Acta Diabetol. 2010 Mar;47(1):15-22.

35. Castaneda C, Layne JE, Munoz-Orians L, Gordon PL, Walsmith J, Foldvari M, et al A randomized controlled trial of resistance exercise training to improve glycemic control in older adults with type 2 diabetes. Diabetes Care. 2002 Dec;25(12):2335 41.

36. Baldi JC, Snowling N. Resistance training improves glycaemic control in obese type 2 diabetic men. Int J Sports Med. 2003 Aug;24(6):419-23.

37. Eriksson BG, Dey DK, Hessler RM, Steen G, Steen B. Relationship between MNA and SF-36 in a free-living elderly population aged 70 to 75 . J Nutr Health Aging 2005 Jul-Aug;9(4):212-20.

38. Doumit J, Nasser R. Quality of life and wellbeing of the elderly in Lebanese nursing homes. Int J Health Care Qual Assur. 2010;23(1):72-93.

39. Kvamme JM, Olsen JA, Florholmen J, Jacobsen BK. Risk of malnutrition and healthrelated quality of life in community-living elderly men and women: the Tromso study. Qual Life Res. 2011 May;20(4):575-82.

40. Mastaglia SR, Seijo M, Muzio D, Somoza J, Nunez M, Oliveri B. Effect of vitamin D nutritional status on muscle function and strength in healthy women aged over sixtyfive years. J Nutr Health Aging. 2011 May;15(5):349-54.

41. Wexler DJ, Grant RW, Wittenberg E, Bosch JL, Cagliero E, Delahanty L, et al. Correlates of health-related quality of life in type 2 diabetes. Diabetologia. 2006 Jul;49(7):1489-97.

42. Ose D, Miksch A, Urban E, Natanzon I, Szecsenyi J, Kunz CU, et al. Health related quality of life and comorbidity. A descriptive analysis comparing EQ-5D dimensions of patients in the German disease management program for type 2 diabetes and patients in routine care. BMC Health Serv Res. 2011;11:179.

43. Herder C, Peltonen M, Koenig W, Sutfels K, Lindstrom J, Martin S, et al. Antiinflammatory effect of lifestyle changes in the Finnish Diabetes Prevention Study. Diabetologia. 2009 Mar;52(3):433-42.

44. Fodor JG, Adamo KB. Prevention of type 2 diabetes mellitus by changes in lifestyle. N Engl J Med. 2001 Aug 30;345(9):696; author reply -7.

45. Scheen AJ. [Clinical study of the month. Prevention of type 2 diabetes in overweight patients with impaired glucose tolerance: efficiency of lifestyle changes]. Rev Med Liege. 2001 Jun;56(6):463-5 